\title{
Amage imajimai sp. nov., a new species of Ampharetidae (Annelida: Polychaeta) from Japanese waters
}

\author{
Michael G. REUSCHER \\ Harte Research Institute for Gulf of Mexico Studies, Texas A\&M University - Corpus Christi, 6300 \\ Ocean Drive, Unit 5869, Corpus Christi, Texas 78412-5869, USA. \\ E-mail: michael.reuscher@tamucc.edu
}

urn:1sid:zoobank.org:author:CEE857C6-DB17-4C9B-BE81-D04AB815E909

\begin{abstract}
A new polychaete species of the family Ampharetidae, Amage imajimai sp. nov., is described from deep waters of Sagami Bay, Japan. It is characterized by the possession of four pairs of branchiae, twelve thoracic uncinigers, eleven abdominal uncinigers, and the lack of thoracic notopodial cirri. The new species is named in honor of the renowned Japanese polychaetologist Minoru Imajima. An identification key for all Amage species from Japanese waters is provided.
\end{abstract}

Keywords. Ampharetidae, Amage, new species, Sagami Bay, Japan.

Reuscher M.G. 2015. Amage imajimai sp. nov., a new species of Ampharetidae (Annelida: Polychaeta) from Japanese waters. European Journal of Taxonomy 154: 1-7. http://dx.doi.org/10.5852/ejt.2015.154

\section{Introduction}

In a recent study on Ampharetidae from Japan many new species and new records were discovered (Imajima et al. 2012, 2013; Reuscher et al. 2015a, 2015b). In the last publication of the series (Reuscher et al. 2015b), a list of all 58 ampharetid species recorded from Japan was provided. Six of these species known to occur in Japanese waters belong to the genus Amage Malmgren, 1866: A. cf. adspersa (Grube, 1863), A. auricula Malmgren, 1866, A. delus (Chamberlin, 1919), A. ehlersi Reuscher, Fiege \& Imajima, 2015, A. longitorus Reuscher, Fiege \& Imajima, 2015 and A. scutata Moore, 1923. During the examination of material from the National Museum of Nature and Science in Tsukuba (Japan), I was able to identify another new species of Amage, which is described here. The new species was collected at a depth of about $1000 \mathrm{~m}$ in Sagami Bay off the southeastern Honshu coast.

\section{Material and methods}

The specimens examined in this study were collected in Sagami Bay during a research cruise in July 1966. They were fixed in 7\% formaldehyde seawater solution and preserved in $70 \%$ ethanol.

Preserved specimens were examined with an Olympus SZX7 stereo microscope and compound microscopes of the models Leica DMLB and Olympus CX41. Pencil drawings were made using a camera lucida, attached to the Leica DMLB. 
The drawings were digitized with a Wacom Intuos drawing tablet and Adobe Illustrator, according to the methods of Coleman (2003). Shadings were added in Adobe Photoshop. The "ID card" (Imajima et al. 2012) was prepared in Adobe Illustrator.

\section{Abbreviations \\ $\mathrm{cs}=$ complete specimen \\ af $=$ anterior fragment}

Types and other specimens are deposited in the following institutions:

NSMT $=$ National Museum of Nature and Science, Japan

SMF $=$ Senckenberg Museum Frankfurt, Germany

Full details for the material deposited at Senckenberg can be found at http://sesam.senckenberg.de/.

\section{Results}

Phylum Annelida Lamarck, 1809

Class Polychaeta Grube, 1850

Order Terebellomorpha Hatschek, 1893

Family Ampharetidae Malmgren, 1866

Subfamily Ampharetinae Malmgren, 1866

Genus Amage Malmgren, 1866

Amage Malmgren, 1866: 370.

Paramage Caullery, 1944: 94.

Egamella Fauchald, 1972: 295.

Mexamage Fauchald, 1972: 309.

\section{Type species}

Amage auricula Malmgren, 1866.

\section{Diagnosis (emended)}

Prostomium with middle lobe surrounded by inflated lobe, lacking glandular ridges. Buccal tentacles smooth. Two to four pairs of cirriform branchiae. Segment II usually without chaetae, or exceptionally with minute chaetae. Thorax with 9-14 uncinigers. Modified or intermediate segments absent. Abdomen with rudimentary notopodia.

\section{Remarks}

The diagnosis was emended to accommodate the synonymy of the monotypic genus Egamella Fauchald, 1972 by Jirkov (2011). Egamella has only two pairs of branchiae and nine thoracic uncinigers. This synonymy needs to be confirmed by the examination of the type specimen of Egamella quadribranchiata Fauchald, 1972. 


\section{Amage imajimai sp. nov. urn:1sid:zoobank.org:act:CCA76C94-C953-418D-AFC9-DDBBD7D99C6D}

Fig. $1 \mathrm{~A}-\mathrm{G}$

\section{Diagnosis}

Four pairs of branchiae. Twelve thoracic uncinigers. Notopodia without ventral cirri. Eleven abdominal uncinigers.

\section{Etymology}

The species is dedicated to the distinguished Japanese polychaete taxonomist Minoru Imajima.

\section{Specimens examined}

\section{Holotype}

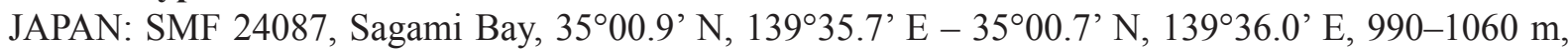
KT-66-12, St. 7, Jul. 1966 (1 cs).

\section{Paratypes}

JAPAN: SMF 24086, same locality as holotype (3 cs); NSMT-Pol. P-600, same locality as holotype (3 cs, 1 af).

\section{Description}

Length of holotype $3.2 \mathrm{~mm}$, width $0.4 \mathrm{~mm}$. Prostomium with middle lobe bearing anterolateral frontal horns, delimited by incision from inflated surrounding lobe (Fig. 1A); prostomium without glandular ridges or eyes. Single tip of smooth buccal tentacle visible in buccal cavity. Four pairs of branchiae in L-shaped arrangement in segments II-IV (Fig. 1B), separated by wide median gap; all branchiae detached from specimen, cirriform, without conspicuous ciliation or annulations; innermost branchiae of anterior transverse row (1) originating from segment II, outermost branchiae of anterior transverse row (2) originating from segment III, median branchiae of longitudinal row (3) originating from segment IV, posterior branchiae of longitudinal row (4) originating from segment V (Fig. 1B). Segment II without chaetae. Notopodia with capillary chaetae from segment III, present in 15 chaetigers; first three notopodia in close succession due to shortness of segments and slightly elevated above following notopodia (Fig. 1C); first notopodia small, increasing in size from first to third pair; notopodial cirri absent. Neuropodial tori with uncini from segment VI, present in 12 thoracic uncinigers; tori without cirri. Continuous ventral shields conspicuous from anterior thorax to thoracic unciniger 9. Modified notopodia or segments absent. Intermediate uncinigers absent. Eleven abdominal uncinigers with small tuberculate rudimentary notopodia. Pinnules with minute tuberculate dorsal cirrus. Rudimentary notopodia and pinnules connected by glandular fold. Pygidium with one pair of digitiform, ventrolateral anal cirri. Left anal cirrus broken off. Thoracic uncini with 7 teeth in 2 staggered row over basal prow and rostral tooth (Fig. 1D-E). Abdominal uncini with numerous teeth in several rows over basal prow and rostral tooth. Tube parchment like with needle like spicules embedded.

\section{Remarks}

In four of the paratypes the buccal tentacles are better visible and clearly smooth. The tuberculate dorsal cirri of the abdominal pinnules are much better developed in the larger paratype specimens (Fig. 1F). The anal cirri are longer and cirriform in the larger paratypes (Fig. 1G). However, they also seem to break off easily as three of the six complete paratypes lack both anal cirri.

The two other Amage species with twelve thoracic uncinigers are $A$. benhami Reuscher, Fiege $\&$ Wehe, 2009 from the northeast Pacific and the Ross Sea and A. longitorus Reuscher, Fiege \& Imajima, 2015 

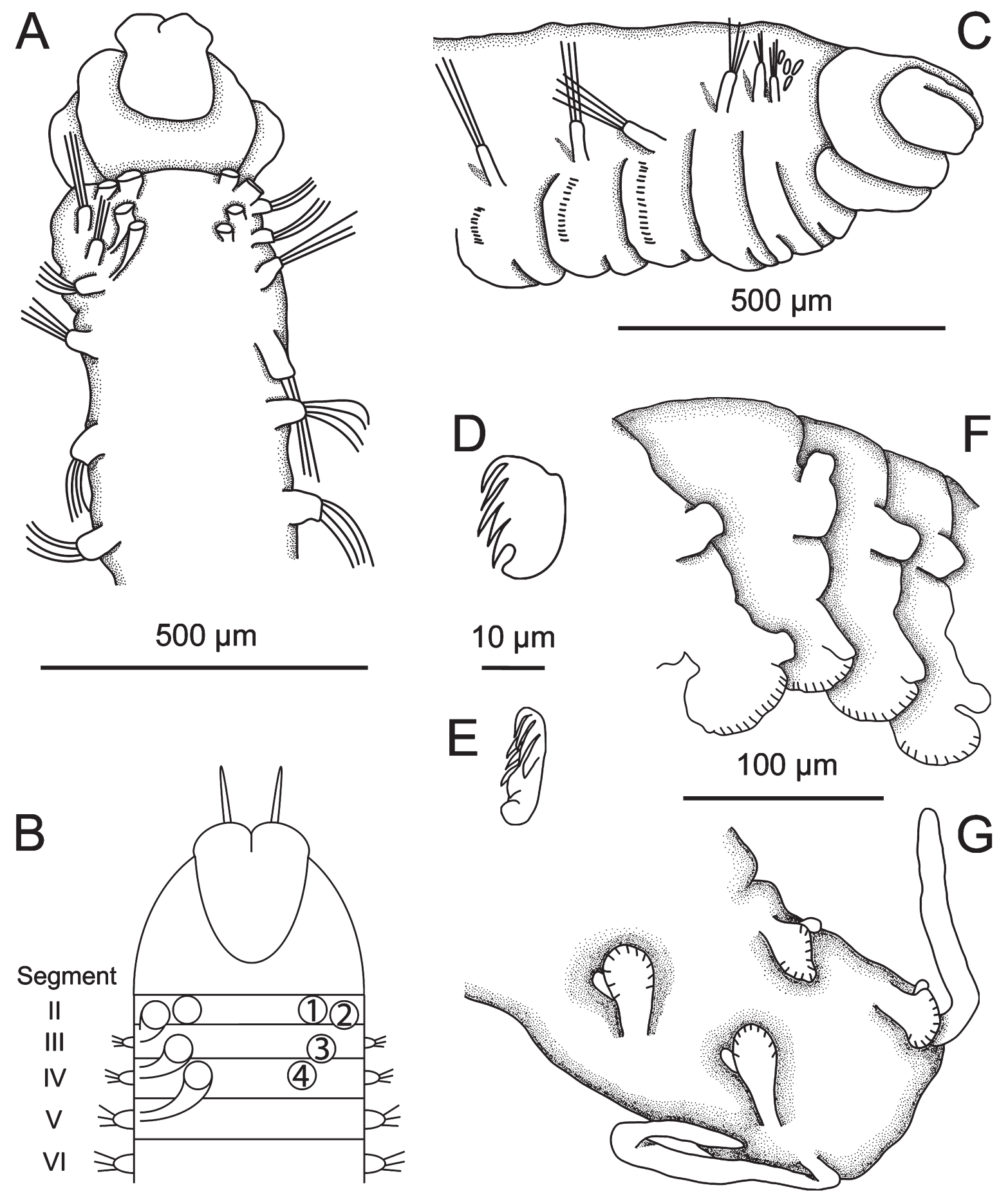

Fig. 1. Amage imajimai sp. nov. A. Anterior end of holotype, dorsal view. B. "ID card". C. Anterior end of holotype, lateral view. D. Thoracic uncinus, lateral view. E. Thoracic uncinus, frontal view. F. Abdominal uncinigers, lateral view (from paratype SMF 24086). G. Posteriormost abdominal uncinigers and pygidium, ventral view (from paratype SMF 24086). 
from Japan. The latter species differs from A. imajimai sp. nov. by the possession of only three pairs of branchiae, the very long tori in the first two thoracic uncinigers and the larger number of abdominal uncinigers (13). A. benhami differs from the new species by the presence of club shaped notopodial cirri and the higher number of abdominal uncinigers (15-16).

Among the other Japanese Amage species A. auricula, A. delus, A. ehlersi and A. scutata have 11 thoracic uncinigers, $A$. cf. adspersa has 14 thoracic uncinigers. A. cf. adspersa, A. auricula and $A$. delus differ from A. imajimai sp. nov. by the presence of notopodial cirri. A. scutata is unusual for the presence of rudimentary notopodia in the anterior segments. A. imajimai sp. nov. has a higher count of abdominal uncinigers (11) than A. auricula (8) and A. ehlersi (10) and a lower count than A. delus (12) and $A$. longitorus (13).

\section{Distribution}

Sagami Bay on the Southeastern Pacific coast of Honshu, in 990-1060 m.

\section{Identification key for Amage species from Japanese waters}

1. 11 or 12 thoracic uncinigers

- 14 thoracic uncinigers Amage cf. adspersa (Grube, 1863)

2. 11 thoracic uncinigers 3

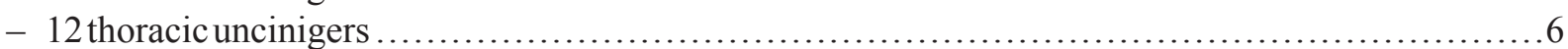

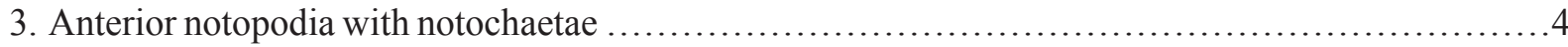

- Anterior notopodia lacking notochaetae ............................Amage scutata Moore, 1923

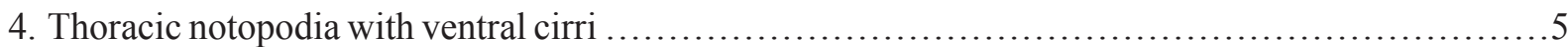

- Thoracic notopodia lacking ventral cirri ...........Amage ehlersi Reuscher, Fiege \& Imajima, 2015

5. 8 abdominal uncinigers ....................................Amage auricula Malmgren, 1866

- 12 abdominal uncinigers ......................................Amage delus (Chamberlin, 1919)

6. 3 pairs of branchiae; anterior neuropodia conspicuously elongated; 13 abdominal uncinigers .Amage longitorus Reuscher, Fiege \& Imajima, 2015

- 4 pairs of branchiae; anterior neuropodia not conspicuously elongated; 11 abdominal uncinigers Amage imajimai sp. nov.

\section{Discussion}

The variety of habitat types and complex interactions of different environmental gradients in the oceans surrounding the Japanese islands attract a variety of species with different physiological and ecological adaptations and thus form the basis of a diverse polychaete fauna. Japan has a wide variety of habitats that are colonized by polychaetes, including bays, deep-sea trenches, hydrothermal vents, and cold seeps, among others (e.g., Juniper \& Sibuet 1987; Horikoshi et al. 1990). The northern part of Japan receives cold water from the Oyashio Current, whereas southern Japan is under the influence of the warm Kuroshio Current (Imajima et al. 2012). Therefore, Japan's polychaete fauna includes Arctic and sub-Arctic species as well as tropical and subtropical species. In the recent series on Ampharetidae from Japan (Imajima et al. 2012, 2013; Reuscher et al. 2015a, 2015b), 60\% of the examined species were new to science and the number of species known from Japan more than doubled. This shows that the current knowledge of species diversity of ampharetid polychaetes from Japan is far from exhaustive and more sampling effort is needed to complete the picture. Amage imajimai sp. nov. is the $59^{\text {th }}$ species of the family Ampharetidae and the seventh species of the genus Amage recorded from Japan. 
Of the other Amage species from Japan, A. delus and A. scutata are known only from northern Honshu, A. cf. adspersa and A. imajimai sp. nov. have only been recorded from Sagami Bay, whereas A. auricula, A. ehlersi and A. longitorus have a wider distribution within Japanese waters.

Within Ampharetidae Amage is probably the most heterogeneous genus as it contains species with two (if the genus Egamella is considered a junior synonym), three and four pairs of branchiae, with nine (Egamella), eleven, twelve, and fourteen thoracic uncinigers, with and without notopodial cirri. A revision is needed to determine if Amage can be upheld as a single genus, or if it should be split into multiple genera.

\section{Acknowledgements}

Minoru Imajima (NSMT) is thanked for the loan of the specimens. I am grateful to Richard D. Kalke and Fabio Moretzsohn (Harte Research Institute, Texas A\&M University-Corpus Christi) for their permissions to use their camera lucida. Paul A. Montagna (Harte Research Institute, Texas A\&M University-Corpus Christi) is thanked for his financial support through the Texas Research Development Post-Doctoral Support Grant.

\section{References}

Caullery M. 1944. Polychètes sédentaires del'expedition du Siboga. Ariciidae, Spionidae, Chaetopteridae, Chlorhaemidae, Opheliidae, Oweniidae, Sabellariidae, Sternaspidae, Amphictenidae, Ampharetidae, Terebellidae. Siboga-Expeditie. Uitkomsten op zoölogisch, botanisch, oceanographisch en geologisch gebied verzameld in Nederlandsch Oost-Indie 1899 - 1900 aan Boord H.M. Siboga onder Commando van Luitenant ter zee 1. kl. G.F. Tydeman 24 (2), Brill, Leiden.

Coleman C.O. 2003. "Digital inking": How to make perfect line drawings on computers. Organisms, Diversity \& Evolution 3, Electronic Supplement 14: 1-14. http://dx.doi.org/10.1078/1439-6092-00081

Fauchald K. 1972. Benthic polychaetous annelids from deep water off western Mexico and adjacent areas in the Eastern Pacific Ocean. Monographs in Marine Biology 7, Allan Hancock Foundation, University of Southern California, Los Angeles.

Horikoshi M., Fujita T. \& Ohta S. 1990. Benthic associations in bathyal and hadal depths off the Pacific coast of north eastern Japan: physiognomies and site factors. Progress in Oceanography 24 (1-4): 331339.

Imajima M., Reuscher M.G. \& Fiege D. 2012. Ampharetidae (Annelida: Polychaeta) from Japan. Part I: The genus Ampharete Malmgren, 1866, along with a discussion of several taxonomic characters of the family and the introduction of a new identification tool. Zootaxa 3490: 75-88.

Imajima M., Reuscher M.G. \& Fiege D. 2013. Ampharetidae (Annelida: Polychaeta) from Japan. Part II: Genera with elevated and modified notopodia. Zootaxa 3647 (1): 137-166. http://dx.doi.org/10.11646/ zootaxa.3647.1.7

Jirkov I.A. (2011) Discussion of taxonomic characters and classification of Ampharetidae (Polychaeta). Italian Journal of Zoology 78 (S1): 78-94.

Juniper S.K. \& Sibuet M. 1987. Cold seep benthic communities in Japan subduction zones: spatial organization, trophic strategies and evidence for temporal evolution. Marine Ecology Progress Series 40: 115-126.

Malmgren A.J. 1866. Nordiska Hafs-Annulater. Öfversigt af Kongliga Vetenskaps-Akademiens Förhandlingar 5: 355-410. 
Reuscher M.G., Fiege D. \& Imajima M. 2015a. Ampharetidae (Annelida: Polychaeta) from Japan. Part III: The genus Amphicteis Grube, 1850 and closely related genera. Journal of the Marine Biological Association of the United Kingdom 95 (5): 929-940. http://dx.doi.org/10.1017/S0025315414001623

Reuscher M., Fiege D. \& Imajima M. 2015b. Ampharetidae (Annelida: Polychaeta) from Japan. Part IV. Miscellaneous genera. Journal of the Marine Biological Association of the United Kingdom 95 (6): 1105-1125. http://dx.doi.org/10.1017/S0025315415000545

Manuscript received: 14 August 2015

Manuscript accepted: 8 October 2015

Published on: 19 November 2015

Topic editor: Rudy Jocqué

Desk editor: Kristiaan Hoedemakers

Printed versions of all papers are also deposited in the libraries of the institutes that are members of the EJT consortium: Muséum national d'Histoire naturelle, Paris, France; Botanic Garden Meise, Belgium; Royal Museum for Central Africa, Tervuren, Belgium; Natural History Museum, London, United Kingdom; Royal Belgian Institute of Natural Sciences, Brussels, Belgium; Natural History Museum of Denmark, Copenhagen, Denmark. 